\title{
STARATEGI PEMASARAN PRODUK TABUNGAN SIMPEDES \\ DALAM MENINGKATKAN JUMLAH NASABAH PADA PT BANK RAKYAT INDONESIA (PERSERO) TbK. KANTOR CABANG SUNGGUMINASA
}

\author{
Asdi 1), Samsul Rizal 2) \\ Email: asdi@unismuh.ac.id ${ }^{1)}$,rizalsamsul09@unismuh.ac.id ${ }^{2}$ \\ ${ }^{1,2}$ Dosen Prodi Manajemen FEB Unismuh Makassar
}

(Diterima: 20 Februari 2019; direvisi: 5 Maret 2019; dipublikasikan: 09 April 2019)

(C2019 -Bongaya Journal for Research in Management STIEM Bongaya. Ini adalah artikel dengan akses terbuka dibawah licenci CC BY-NC-4.0 (https://creativecommons.org/licenses/by-nc/4.0/ ).

\begin{abstract}
Abstrak: Penelitian ini bertujuan untuk mengetahui bagaimana penerapan strategi pemasaran produk tabungan Simpedes dalam meningkatkan jumlah nasabah pada Bank Rakyat Indonesia (Persero) Tbk. Kantor Cabang Sungguminasa. Penelitian dilakukan dengan menjaring sebanyak 50 orang nasabah sampel melalui teknik combined sampling yaitu kombinasi dari teknik quota sampling, aksidental sampling, dan purposive sampling. Data primer diperoleh dari responden melalui teknik wawancara selanjutnya diolah dengan dengan mengidentifikasi berbagai factor dalam penerapan strategi pemasaran produk tabungan Simpedes BRI yaiyu factor internal dan eksternal baik yang berupa peluang maupun yangh berupa ancaman yang selanjutnya dianalisis dengan menggunakan analisis SWOT.Hasil analisis data menggambarkan bahwa posisi produk tabungan simpedes BRI pada PT. Bank Rakyat Indonesia (Persero) Tbk. Kantor Cabang Sungguminasa memberikan peluang yang merupakan kekuatan pendorong dalam menerapkan strategi pemasaran yang dapat meningkatkan jumlah nasabah pada PT. Bank Rakyat Indonesia (Persero) Tbk. Kantor Cabang Sungguminasa.
\end{abstract}

Kata kunci: Strategi Pemasaran Produk Simpedes BRI

\section{PENDAHULUAN}

Tuntutan masyarakat terhadap dunia perbankan saat ini semakin meningkat, dimana masyarakat tidak hanya memandang sebuah bank sebagai sarana untuk menyimpan uang yang lebih aman, namun lebih dari itu, mereka mengharapkan hasil investasi yang lebih tinggi, sehingga menciptakan suasana persaingan antar bank dalam penggalangan dana nasabah yang semakin ketat dan di sisi lain pemerintah membatasi bank dalam memberikan suku bunga produk simpanan tidak melebihi bunga perjanjian Bank Indonesia.
Sebuah bank, tidaklah cukup hanya dengan memberikan jasa-jasa keuangan saja, tetapi yang terpenting adalah bagaimana cara untuk meningkatkan mutu dari pemberian jasajasa tersebut. Bank harus beroperasi secara sehat, sehingga kepentingan semua pihak terjaga dan kelanjutan hidup bank terjamin.

Oleh karena itu, perkembangan mutakhir dalam perbankan telah mendorong Bank Rakyat Indonesia untuk mencari jasa-jasa (service) baru yang dapat ditawarkan kepada nasabah, hal ini sejalan dengan visi dari Bank Rakyat Indonesia untuk menjadi bank komersial terkemuka yang 
selalu mengutamakan kepuasan nasabah serta misi Bank Rakyat Indonesia yang antara lain sebagai berikut:

1. Melakukan kegiatan perbankan yang terbaik dengan mengutamakan pelayanan kepada usaha mikro, kecil dan menengah untuk menunjang peningkatan ekonomi masyarakat.

2. Memberikan pelayanan prima kepada nasabah melalui jaringan kerja yang tersebar luas dan didukung oleh sumber daya manusia yang profesional dan teknologi informasi yang handal dengan melaksanakan manajemen resiko serta praktek Good Corporate Governance (GCG) yang sangat baik.

3. Memberikan keuntungan dan manfaat yang optimal kepada pihak-pihak yang berkepentingan (stakeholders).

Meningkatkan citra Bank Rakyat Indonesia sebagai lembaga keuangan perbankan, maka salah satu upaya yang dilakukan dalam rangka upaya untuk meningkatkan jumlah nasabah adalah dengan menawarkan berberapa produk tabunagan yang salah sarunya adalah Produk Tabungan Simpedes BRI.

Kegiatan pemasaran selalu ada dalam setiap usaha,baik perusahaan yang beriorientasi profit maupun usaha-usaha sosial. Pentingnya pemasaran dilakukan dalam rangka memenuhi kebutuhan dan keinginan masyarakat akan suatu produk atau jasa. Pemasaran akan menjadi semakin penting dengan semakin meningkatnya pengetahuan masyarakat. Kemudian juga dalam rangka menghadapi para pesaing dari waktu ke waktu semakin meningkat.

Dewasa ini kegiatan pemasaran tidak hanya menopoli perusahaan yang beriorientasi profit saja, bahkan sudah mulai menggunakan pemasaran dalam rangka memenuhi kebutuhan dan keinginan konsumen. Menurut Assauri (2008 :168) mengemukakan bahwa strategi pemasaran adalah serangkaian tujuan dan sasaran,kebijakan dan aturan yang memberi arah kepada usaha-usaha pemasaran perusahaan dari waktu ke waktu, pada masing-masing tingkatan dan acuan serta alokasinya, terutama sebagai tanggapan perusahaan dalam menghadapi lingkungan dan keadaan persaingan yang selalu berubah

Lain halnya menurut Gitosudarmo (2008 :182) mendefinisikan bahwa bauran pemasaran sebagai alat bagi pengusaha untuk mempengaruhi nasabahnya dapat menjadi kenal kemudian menyenangi dan kemudian melakukan transaksi pembelian serta akhirnya nasabah itu menjadi puas.

Melakukan pemasaran produk Simpedes, BRI perlu mengemas kegiatan pemasarannya secara terpadu dan terus menerus melakukan riset pasar. Pemasaran harus dikelolah secara profesional, sehingga kebutuhan dan keinginan pelanggan akan segera terpenuhi.

Berdasarkan pemaparan di atas, maka dilakukan penelitian dengan tujuan untuk mengetahui apakah strategi pemasaran produk tabungan Simpedes dapat meningkatkan jumlah nasabah pada PT. Bank Rakyat Indonesia (Persero) Tbk Cabang Sungguminasa Kabupaten Gowa.

\section{TINJAUAN TEORI Strategi Pemasaran Bank}

Dewasa ini kegiatan pemasaran tidak hanya monopoli perusahaan yang berorientasi profit saja, bahkan usaha badan sosial sudah 
mulai menggunakan pemasaran dalam rangka memenuhi kebutuhan dan keinginan konsumen. Menurut Assauri (2008:168) mengemukankan bahwa strategi Pemasaran adalah serangkaian tujuan dan sasaran, kebijakan dan aturan yang memberi arah kepada usaha-usaha pemasaran perusahaan dari waktu ke waktu, pada masingmasing tingkatan dan acuan serta alokasinya, terutama sebagai tanggapan perusahaan dalam menghadapi lingkungan dan keadaan persaingan yang selalu berubah

Lain halnya menurut Gitosudarmo (2008 : 182) mendefenisikan bahwa bauran pemasaran sebagai alat bagi pengusaha untuk mempengaruhi nasabah agar nasabahnya dapat menjadi kenal kemudian menyenangi dan kemudian melakukan transaksi pembelian serta akhirnya nasabah itu menjadi puas.

Konsep pemasaran bank sebenarnya tidak banyak berbeda dengan konsep pemasaran untuk sektor bisnis yang lain, seperti sektor industri manufaktur, sektor bisnis jasa dan lain-lain. Perbankan merupakan salah satu jenis industri jasa, sehingga konsep pemasarannya lebih cenderung mengikuti konsep untuk produk jasa, yang membedakan perbankan dari industri jasa lainnya adalah banyaknya ketentuan dan peraturan pemerintah yang membatasi penggunaan konsep-konsep pemasaran, mengingat industri perbankan merupakan industri yang sangat dipengaruhi oleh tingkat kepercayaan masyarakat.

Dalam pemasaran jasa oleh Boom dan Bitner (Kotler,1997:88) menyarankan tambahan 3P yaitu P5= People,P6=Physical Evidence dan $\mathrm{P} 7=$ Process. Sehingga bauran pemasaran atau marketing mix terdiri dari 7P, (Product, price, place, promotion, people, physical evidence, process) yaitu :

\section{a. Produk (Product)}

Produk perbankan adalah instrumen/perangkat yang dibeli dan dijual oleh bank. Produk yang dibeli oleh bank sangat banyak jumlahnya, karena bank dapat menciptakan berbagai jenis produk sesuai dengan keinginan nasabah. Jasa bank yang diberikan hendaknya memperhatcikan kualitas dan kuantitas bankir, kualitas yang disajikan oleh para bankir termasuk waktu pelayanan, teknologi atau peralatan yang digunakan dalam melayani nasabah, kemasan atau bentuk jasa yang diberikan, merek bagi setiap jasa yang ditawarkan dan adanya jaminan terhadap jasa yang diberikan.

\section{b. Harga (Price)}

Harga merupakan salah satu aspek penting dalam kegiatan marketing mix. Penentuan harga menjadi sangat penting untuk diperhatikan mengingat harga sangat menentukan laku tidaknya produk dan jasa perbankan. Salah dalam menentukan harga akan berakibat fatal terhadap produk yang ditawarkan.

\section{c. Lokasi (Place)}

Kegiatan pemasaran yang ketiga adalah penentuan lokasi kantor cabang bank, baik untuk cabang utama, cabang pembantu atau kantor kas. Penentuan lokasi kantor beserta sarana dan prasarana pendukung menjadi sangat penting, hal ini disebabkan agar nasabah mudah menjangkau setiap lokasi bank yang ada. Demikian pula sarana dan 
prasarana yang harus memberikan rasa yang aman kepada seluruh nasabahnya.

\section{d. Promosi (Promotion)}

Promosi merupakan kegiatan marketing mix yang terakhir. Kegiatan ini merupakan kegiatan yang sama pentingnya dengan ketiga kegiatan dalam marketing mix, baik produk, harga dan lokasi. Dalam kegiatan ini setiap bank berusaha untuk mempromosikan seluruh produk dan jasa yang dimilikinya baik langsung maupun tidak langsung.

\section{e. Orang (People)}

Yang dimaksud partsipan disini adalah karyawan penyedia jasa layanan maupun penjualan, atau orang-orang yang terlibat secara langsung maupun tidak langsung dalam proses layanan itu sendiri.

\section{f. Bukti Fisik (Phisical of Evidance)}

Terdiri dari adanya logo atau simbol perusahaan, moto, fasilitas yang dimiliki, seragam karyawan, laporan, kartu nama, dan jaminan perusahaan

\section{g. Proses (Process)}

Proses adalah kegiatan yang menunjukan bagaimana pelayanan diberikan kepada konsumen selama melakukan pembelian produk atau jasa.

\section{Produk Tabungan BRI Simpedes}

Tabungan BRI Simpedes adalah simpanan masyarakat dalam bentuk tabungan dengan mata uang rupiah, yang dapat dilayani di kantor cabang BRI/ KCP BRI/ BRI unit/ Teras BRI, yang jumlah penyetoran dan pengambilan tidak dibatasi baik frekuensi maupun jumlahnya, sepanjang memenuhi ketentuan yang berlaku.
Keunggulan tabungan Simpedes Bank BRI adalah :

a) Jaringan yang tersebar luas diseluruh indonesia dan terhubung secara Online.

b) Peluang besar untuk memenangkan hadiah, total milyaran rupiah.

c) Dilengkapi dengan BRI card (kartu BRI) yang berfungsi sebagai kartu ATM dan kartu debit dengan fitur transaksi yang lengkap.

d) Pembukaan Rekening Tabungan Simpedes BRI yang mudah dan praktis, diseluruh unit kerja BRI.

e) Jumlah dan frekuensi setor dan ambil tidak dibatasi sepanjang memenuhi ketentuan yang berlaku.

f) Jaringan BRI card

\section{Analisis S Analisis SWOT}

Menurut Freddy (2013 : 20) mengemukakan bahwa SWOT adalah singkatan dari lingkungan internal Strengths dan Weaknesses serta lingkungan eksternal Opportunities dan Threats yang dihadapi dunia bisnis. Analisis SWOT membandingkan antara faktor eksternal peluang (Opportunities) dan ancaman (Threats) dengan faktor internal kekuatan (Strengths), dan kelemahan (Weaknesses)".

$$
\text { Sedangkan Kotler (2008: 88) }
$$

mengemukakan bahwa analisis SWOT adalah evaluasi terhadap keseluruhan kekuatan, kelemahan, peluang dan ancaman disebut analisis SWOT.

Kinerja perusahaan dapat ditentukan oleh kombinasi faktor internal dan eksternal. Kedua faktor tersebut harus dipertimbangkan dalam analisis SWOT. SWOT adalah singkatan dari 
lingkungan Internal Strengths dan Weaknesses serta lingkungan eksternal Opportunities dan Thearts yang dihadapi dunia bisnis. Analisis SWOT membandingkan antara faktor eksternal Peluang dan Ancaman dan faktor internal Kekuatan dan Kelemahan.

\section{METODE}

\section{Pendekatan Penelitian}

Pendekatan penelitian yang digunakan dalam penelitian ini adalah pendekatan deskriptif kuantitatif. Santoso (2012) menjelaskan pendekatan deskriptif kuantitatif merupakan penelitian dengan mendeskripsikan secara sistematis, faktual dan akurat terhadap kondisi dan fenomena yang terjadi berdasarkan data dan informasi yang didapatkan dalam penelitian. Dalam penelitian ini, digunakan metode kuantitatif karena angka, mulai dari pengumpulan data, penafsiran data tersebut, serta menampilkan hasilnya. Selain itu juga akan digunakan tabel, grafik dan diagram.

\section{Populasi dan Sampel}

Populasi penelitian ini adalah nasabah tabungan simpedes selama 2016 pada PT. Bank Rakyat Indonesia (Persero) Tbk. Cabang sungguminasa Kabupaten Gowa yang berjumlah 1900 orang nasabah.

Selanjutnya untuk menentukkan sampel yang akan dijadikan responden maka peneliti menggunakan teknik double Sampling yaitu :

a. Menentukan banyaknya nasabah sampel yang akan dijadikan responden penelitian menggunakan teknik Quota Sampling yaitu sebanyak 50 orang nasabah, jumlah ini dianggap cudah dapat mewakili populasi, serta mempertimbangkan kemampuan peneliti untuk dapat menjangkau dan berkominikasi dengan para nasabah sampel yang dipilih sebagai responden.

b. Memilih nasabah sampel dengan menggunakan teknik Purposive Sampling yaitu dengan sengaja memilih beberapa nasabah tertentu karena yang bersangkutan yang dianggap representatif mewakili nasabah lainnya.

\section{Metode Pengumpulan Data}

Dalam penelitian ini metode pengumpulan data yang digunakan adalah sebagai berikut :

1. Dokumentasi, yaitu teknik pengumpulan data dan informasi dari buku-buku, jurnal, internet, dan skripsi yang berkaitan dengan penelitian sehingga dapat mendukung dan menambah kepercayaan dan pembuktian suatu kejadian.

2. Angket (Kuesioner), yaitu daftar pertanyaan yang diberikan kepada orang lain yang bersedia memberikan respons (responden) sesuai dengan permintaan pengguna.

3. Wawancara (Interview), yaitu suatu cara pengumpulan data yang digunakan untuk memperoleh informasi lansung dari sumbernya.

4. Pengamatan (observation), yaitu melakukan pengamatan secara langsung ke objek penelitian untuk melihat dari kegiatan yang dilakukan

\section{Metode Analisis Data}

Metode Analisis yang digunakan adalah analisis deskriptif dengan pendekatan analisis swot. Analisis ini digunakan untuk memberi 
gambaran tentang kekuatan,kelemahan,peluang dan ancaman yang dimiliki Bank Rakyat Indonesia Kantor Cabang Sungguminasa dalam melakukan strategi pemasaran produk-produk Bank Rakyat Indonesia pada umumnya yang salah satunya adalah produk Simpedes BRI dalam upayanya untuk dapat mencapai target pasar serta yang ditandai dengan adanya peningkatan jumlah nasabah.

\section{HASIL DAN PEMBAHASAN Analisis SWOT Produk Simpedes}

Analisis SWOT adalah mengidentifikasi berbagai faktor secara sistematis untuk merumuskan strategi pemasaran produk tabungan simpedes. Analisis ini didasarkan pada logika yang dapat memaksimalkan kekuatan (Strength) dan peluang (Opportunities), namun secara bersamaan dapat meminimalkan kelemahan (Weakness) dan ancaman (Threat).

Dari hasil analisis nampak bahwa posisi produk tabungan simpedes terletak pada sel I yang mempunyai kekuatan lebih besar yaitu $(2,10)$ dan kelemahan $(1,00)$ sehingga hasilnya $(1,10)$.Dan mempunyai peluang $(2,25)$,ancaman $(0,85)$ sehingga hasilnya 1,40 .Dengan demikian berdasarkan analisis swot diatas strategi pemasaran produk tabungan simpedes yang dilakukan oleh BRI dapat meningkatkan jumlah nasabah.

\section{Matriks SWOT}

Matriks SWOT untuk produk Simpedes adalah sebagai berikut:
Tabel 2

Matriks SWOT Produk Simpedes

\begin{tabular}{|c|c|c|}
\hline IFAS & $\begin{array}{l}\text { Kekuatan (S) } \\
\text { a. Setoran awal yang } \\
\text { kecil } \\
\text { b. Kantor BRI yang } \\
\text { sudah banyak di desa- } \\
\text { desa dan dekat pasar } \\
\text { c. Tingkat keseringan } \\
\text { melakukan promosi } \\
\text { penjualan sehingga } \\
\text { nasabah mengenal } \\
\text { produk yang } \\
\text { ditawarkan } \\
\text { d. Kemudahan dalam } \\
\text { betransaksi } \\
\text { e. Fasilitas bisa } \\
\text { digunakan melatui } \\
\text { Phone Banking }\end{array}$ & $\begin{array}{l}\text { Kelemahan (W) } \\
\text { a. Tidak semua } \\
\text { nasabah memiliki } \\
\text { kartu ATM } \\
\text { b. Sarana ATM } \\
\text { yang masih } \\
\text { terbatas } \\
\text { c. Suku bunga yang } \\
\text { relatif kecil } \\
\text { d. Pengetahuan } \\
\text { nasabah tentang } \\
\text { fasilitas Phone } \\
\text { Banking masih } \\
\text { lemah. }\end{array}$ \\
\hline
\end{tabular}

\begin{tabular}{|c|c|c|}
\hline $\begin{array}{l}\text { Peluang (O) } \\
\text { a. Banyaknya petani di } \\
\text { Kota Sungguminasa } \\
\text { yangmembutuhkan } \\
\text { pinjaman di Bank. } \\
\text { b.Munculnya UKM baru } \\
\text { yangmembutuhkan } \\
\text { pinjaman untukmodal } \\
\text { usaha. } \\
\text { c. Dukungan pemerintah } \\
\text { daerahsetempatuntuk } \\
\text { menunjangusaha } \\
\text { perbankan } \\
\text { d. Meningkatrya } \\
\text { pengetahuan } \\
\text { masyarakat tentang } \\
\text { pentingnya menabung } \\
\end{array}$ & $\begin{array}{l}\text { Strategi SO } \\
\text { a. Memanfaatkan } \\
\text { seluruhk kekuatan } \\
\text { produk simpedes } \\
\text { sehingga dapat } \\
\text { menambahjumlah } \\
\text { nasabah } \\
\text { b. Menarik nasabah } \\
\text { denganmemberikan } \\
\text { pinjaman yang sesuai } \\
\text { dengan kriteria } \\
\text { persyaratankredit } \\
\text { c. Meningkatkankineja } \\
\text { pemasaran melalui } \\
\text { strategi distribusi } \\
\text { dengan cara } \\
\text { pembukaankantor } \\
\text { unit di pedesaan atas } \\
\text { kerjasama dengan } \\
\text { pemerintah daerah } \\
\text { demberikan edukas } \\
\text { kepada masyarakat } \\
\text { melalui program } \\
\text { promosi dengan } \\
\text { menekankanmanfaat } \\
\text { memiliki rekening } \\
\text { tabungandi Bank }\end{array}$ & $\begin{array}{l}\text { Strategi WO } \\
\text { a. Menyediakan } \\
\text { sarana ATM di } \\
\text { BRI Unit agar } \\
\text { nasabah mudah } \\
\text { bertransaksi } \\
\text { b. Menjelaskan } \\
\text { kepada nasabah } \\
\text { tentang } \\
\text { pengguna an } \\
\text { fasilitas phone } \\
\text { banking } \\
\text { c. Menjelaskan } \\
\text { manfaat memiliki } \\
\text { rekening tabungan } \\
\text { dengan } \\
\text { menggunakan } \\
\text { fasilitas kartu } \\
\text { debet }\end{array}$ \\
\hline \begin{tabular}{l}
\multicolumn{1}{c}{ Ancaman $(\mathrm{T})$} \\
Bank-bank pesaing \\
membuka cabang \\
Tanif bank pesaingyang \\
lebih kompetitif.
\end{tabular} & \begin{tabular}{l}
\multicolumn{1}{c}{ Strategi ST } \\
pembenahan dan \\
pengembangan terhadap \\
kualitas pelayanan \\
sehingga dapat \\
memberikan \\
kepercayaan kepada \\
nasabah \\
Mempertahankan \\
nasabah
\end{tabular} & \begin{tabular}{l}
\multicolumn{1}{c}{ Strategi WT } \\
Meningkatkansuku \\
bunga agar lebih \\
kompetitif. \\
Nasabah harus \\
memiliki ATM
\end{tabular} \\
\hline
\end{tabular}

Sumber : Data diolah, 2019

\section{Alternatif Strategi}

Berdasarkan analisis menggunakan model Matriks SWOT seperti pada tabel 2 diatas maka dapat dibuat berbagai alternatif strategi yang dapat dikembangkan oleh PT. Bank Rakyat Indonesia (Persero) Tbk Kantor Cabang Sungguminasa adalah sebagai berikut : 
1) Strategi SO (Strategi Kekuatan - peluang). Strategi ini menggunakan kekuatan untuk memanfaatkan peluang. Strategi SO untuk produk Simpedes yaitu :

a. Memanfaatkan seluruh kekuatan produk simpedes sehingga dapat menambah jumlah nasabah.

b. Memperkenalkan produk dan menarik nasabah dengan memberikan pinjaman yang sesuai dengan kriteria persyaratan kredit.

2) Strategi ST (kekuatan - Ancaman), yaitu Strategi dengan menggunakan kekuatan yang dimiliki untuk menghadapi ancaman yaitu :

a. Pembenahan dan pengembangan terhadap kualitas pelayanan sehingga dapat memberikan kepercayaan kepada nasabah.

b. Mempertahankan nasabah, hal ini dapat dilakukan dengan memberikan pelayanan yang bermutu sehingga menciptakan kepuasan bagi nasabah.

3) Strategi WO (kelemahan - peluang), yaitu strategi untuk mengatasi kelemahan dengan memanfaatkan peluang yang ada dengan :

a. Menyediakan sarana ATM di BRI Unit agar nasabah mudah bertransaksi. Hal tersebut mengindikasikan bahwa peluang yang ada pada PT. Bank Rakyat Indonesia sangat penting dan harus dimanfaatkan oleh perusahaan karena peluang tersebut sangat berpengaruh untuk pengembangan unit-unit yang tersebar.

b. Menjelaskan kepada nasabah tentang penggunaan fasilitas phone banking agar nasabah diharapkan dapat bertransaksi dengan mudah.

4) Strategi WT (kelemahan - ancaman), yaitu merupakan strategi untuk mengatasi kelemahan dengan cara menghindari ancaman :

a. Meningkatkan suku bunga agar lebih kompetitif, PT. Bank Rakyat Indonesia (Persero) cabang Sungguminasa harus berfikir inovatif guna untuk memberikan keselarasan antara permintaan nasabah.

b. Nasabah harus memiliki ATM agar nasabah lebih mudah dan tanpa harus antri dalam bertransaksi.

\section{Deskripsi Peningkatan Jumlah Nasabah Tabungan Simpedes}

Bank mempunyai dua aktivitas utama yaitu menghimpun dana dan menyalurkan dana kemasyarakat yang membutuhkan. Sedangkan tabungan adalah salah satu bentuk jasa yang dilakukan oleh bank dalam menghimpun dana. Dalam meningkatkan jumlah tabungan, mempertahankan nasabah dan menarik nasabah baru maka bank dituntut untuk melakukan kegiatan pemasaran yang lebih baik dan efektif dalam mencari solusi dan strategi untuk dapat terus bertahan dalam persaingan dunia perbankan yang ketat. 
Bank BRI merupakan salah satu bank yang terpercaya yang memiliki jaringan yang terluas, saat ini memiliki beberapa produk unggulan yang dapat bersaing dari segi teknologi maupun kedekatan pada masyarakat.Berikut perkembangan jumlah tabungan simpedes periode desember 2015 sampai dengan periode desember 2017 nampak pada tabel 3 :

Tabel 3

Peaingkatan Jemlah Nasabah

\begin{tabular}{|c|c|c|c|c|c|}
\hline No & Tabun & $\begin{array}{c}\text { Jumlah } \\
\text { Nasabah }\end{array}$ & $\begin{array}{c}\text { Peningkatan } \\
\text { Naghah }\end{array}$ & Pesentase & Ket \\
\hline 1 & 2015 & 5.800 & - & - & - \\
\hline 2 & 2016 & 28.120 & 22240 & $378,23 \%$ & Naik \\
\hline 3 & 2017 & 35.00 & 6.800 & $24,47 \%$ & Najk \\
\hline
\end{tabular}

Sumber PT. Bukk Rakyat Indonesa (Pessev) Thk Kantor Cabang Sungsaminase, 2019

Pada tabel diatas menunjukkan bahwa pada tahun 2015 jumlah nasabah simpedes 5.880 nasabah. Kemudian pada tahun 2016 meningkat menjadi 28.120 nasabah $(378,23 \%)$ dan pada tahun 2017 meningkat menjadi 6.880 nasabah (24,47\%), maka dapat disimpulkan bahwa jumlah tabungan simpedes mengalami peningkatan setiap tahunnya dengan diterapkannya strategi analisis swot. Dengan demikian hipotesis yang peneliti yaitu diduga bahwa strategi pemasaran produk tabungan simpedes dapat meningkatkan jumlah nasabah pada PT. Bank Rakyat Indonesia (Persero) Tbk Kantor Cabang Sungguminsa diterima.

\section{KESIMPULAN DAN SARAN}

Berdasarkan hasil penelitian, maka dapat disimpulkan bahwa :

1. Dari hasil identifikasi faktor strategi internal dan faktor strategi eksternal maka diketahui posisi internal dan eksternal produk tabungan simpedes yang memiliki posisi kompetitif pasar yang kuat sehingga PT.
Bank Rakyat Indonesia (Persero) Tbk Kantor Cabang Sungguminasa harus tetap melakukan upaya-upaya dalam meningkatkan kualitas produk pelayanan dan distribusi produk.

2. Terdapat empat alternatif strategi yang dapat diterapkan PT. Bank Rakyat Indonesia (Persero) Tbk Kantor Cabang Sungguminasa sehubungan dengan perkembangan bisnis dan perubahan kondisi pasar yang terjadi berdasarkan faktor-faktor internal dan faktor-faktor eksternal produk tabungan simpedes. Dari empat strategi tersebut yaitu strategi (SO,WO,ST,WT) dapat diterapkan dalam pengembangan strategi yang dapat disarankan pada manajemen PT. Bank Rakyat Indonesia (Persero) Tbk Kantor Cabang Sungguminasa.

Hasil penelitian ini memberi masukan saran kepada PT. Bank Rakyat Indonesia (Persero) Tbk Kantor Cabang Sungguminasa agar memperhatikan strategi produk dan terus menerus meningkatkan kualitas produk, fasilitas yang tersedia dan pelayanan terhadap nasabah. Selain itu, PT. Bank Rakyat Indonesia (Persero) Tbk Kantor Cabang Sungguminasa dapat memanfaatkan perkembangan teknologi dalam era internet dengan memaksimalkan websitenya untuk berpromosi dan memberikan informasi-informasi mengenai produk tabungan simpedes dan produk tabungan lainnya. 
Asdi, Samsul Rizal, Starategi Pemasaran Produk Tabungan Simpedes Dalam Meningkatkan Jumlah Nasabah pada PT Bank Rakyat Indonesia (Persero) Tbk.

Kantor Cabang Sungguminasa| $\mathbf{2 5}$

\section{DAFTAR RUJUKAN}

Anonim. Undang-Undang Perbankan No. 10 Tahun 1998. Jakarta: PT. Rajawali Pers

Assauri, Sofyan. 2008. Manajemen Pemasaran. Edisi kedua. Cetakan kedelapan. Jakarta: PT. Raja Grafindo Persada

Gitosudarmo, Indriyo. 2008. Manajemen Pemasaran. Edisi kedua. Cetakan keenam. Yogyakarta: BPFE

Iman Sentot, Wahjono. 2010. Manajemen Pemasaran Bank. Edisi pertama. Cetakan pertama, Yogyakarta: PT. Graha Ilmu

Infonabung.blogspot.com/2013/06/simpedesBRI.html?m=1 (Diakses tanggal 14 Maret 2014)

Kasmir. 2002. Dasar-Dasar Perbankan. Jakarta : PT. Raja Grafindo Persada

2008. Manajemen Perbankan. Edisi revisi. Cetakan kedelapan. Jakarta: PT. Grafindo Persada

Kotler dan Gary Amstrong. 2001. Prinsip-prinsip Pemasaran. Terjemahan damos sihombing. Edisi 8. Jakarta: Erlangga
Kotler, Philip. 2008. Manajemen Pemasaran. Terjemahan Hendra Teguh. Edisi kedua belas. Cetakan kedua. Jakarta: PT. Prenhalindo

Lupiyoadi, Rambat. 2001. Manajemen Pemasaran Jasa. Edisi pertama, Jakarta. Salemba Empat.

Murti, Sumarni, 2002, Manajemen Pemasaran Bank, edisi revisi, cetakan pertama, Yogyakarta: PT Liberty

Siregar, Syofian, 2012. Statistik Deskriptif Untuk Penelitian, Edisi 1-3, Jakarta: Rajawali Pers.

Sutojo, Siswanto dan F. Kleinsteuber. 2002. Strategi Manajemen Pemasaran. Cetakan pertama. Jakarta: PT. Damar Mulia Pustaka

Yamit, Zulian. 2002. Manajemen Kualitas Jasa. Edisi 1. Cetakan 1. Jakarta: PT Ekonisia

Freddy, Rangkuti. 2013. Analisis SWOT Teknik Membedah Kasus Bisnis. Cetakan ketujuhbelas. Jakarta: PT. Gramedia Pustaka Utama 2008. Analisis SWOT Teknik Membedah Kasus Bisnis. Cetakan kelimabelas. Jakarta: PT. Gramedia Pustaka Utama 